\title{
Notas sobre a presença do Novo-romantismo na formulação teórica de metamodernismo de Timotheus Vermeulen e Robin Van Den Akker
}

\author{
Antonio Carlos Vargas ${ }^{1}$
}

Resumo: O artigo analisa a presença do Novo Romantismo, indicado por Vermeulem e Van der Akker, na formulação do conceito de metamodernismo. Apresenta uma breve historicidade da permanência do ideário romântico ao longo da modernidade e pós-modernidade, ao tempo em que agrega o conceito de romantismo, apresentado pelos sociólogos Michel Löwy e Robert Sayre para tornar mais compreensíveis as causas pelas quais as manifestações artísticas, que preservam elementos oriundos do romantismo, persistem na contemporaneidade. O texto se propõe explicativo, apontando questões que pretendem auxiliar no entendimento das causas pelas quais Vermeulem e Van der Akker identificam a presença do romantismo como um elemento fundamental na elaboração conceitual do metamodernismo.

Palavras-chave: Metamodernismo; pós-modernismo; arte contemporânea

Notes on the presence of New Romanticism in the theoretical formulation of the metamodernism of Timothy Vermeulen and Robin Van Den Akker

\begin{abstract}
The article analyzes the presence of the New Romanticism indicated by Vermeulem and Van der Akker in the formulation of the concept of metamodernism. It presents a brief historicity of the permanence of the romantic ideology throughout modernity and postmodernity. While adding the concept of romanticism, presented by the sociologists Michel Löwy and Robert Sayre, to make more understandable why artistic manifestations preserving elements originally from romanticism persist in contemporaneity. The text shows itself in an explanatory manner, pointing out questions intended to help in the understanding of the causes by which Vermeulem and Van der Akker identify the presence of romanticism as a fundamental element in the conceptual elaboration of metamodernism
\end{abstract}

Keywords: Metamodernism; postmodernism; contemporary art

\footnotetext{
1 Pós-Doutorado na Universitat de Barcelona (1996), Doutorado em Artes/Pintura na Universidad Complutense de Madrid (1992), Bacharelado em Pintura na Universidade Federal do Rio Grande do Sul (1986). Atualmente Professor de graduação e pós-graduação da Universidade do Estado de Santa Catarina - CEART/UDESC. Artista visual com exposições no Brasil e exterior, autor de diversos artigos e capítulos de livros.
}

Email: acvargass@gmail.com; ORCID: https://orcid.org/0000-0001-8458-3909 


\section{Introdução ao conceito de metamodernismo formulado por Vermeulem e Van der Akker}

Embora reconheçam a existência anterior do termo, Timotheus Vermeulem e Robin Van der Akker apresentam, pela primeira vez, seu conceito de metamodernismo em 2010, no volume 2 do Journal of AESTHETICS \& CULTURE, sendo premissa de base para formulação, a identificação de comportamentos que expressam um sentimento de desacordo com os preceitos estéticos da desconstrução, da parataxe e do pastiche, em favor de noções estético-éticas de reconstrução, do mito e da metaxis. O metamodernismo passa a ser entendido como epistemologicamente "com", ontologicamente "entre" e historicamente "além" do modernismo e do pós-modernismo, sendo particularmente significativo desta sensibilidade a presença de elementos oriundos do romantismo (2010, p.02).

Vermeulen e Van den Akker matizam que, enquanto alguns autores apontam sinais do declínio do pós-modernismo por diferentes causas - que vão de mudanças climáticas, crise financeira, ataques terroristas, à revolução digital - outros sustentam este declínio como consequência de mudanças graduais menos tangíveis e, por fim, outros ainda indicam o surgimento de diferentes modelos de identidades políticas, variando do pós-colonialismo global a teoria queer (Vermeulem e Akler, 2010, p. 02).

Tomando como ponto de partida uma provocação de Linda Hucheon, em The politics of Posmodernity ${ }^{2}$ a qual sustenta a necessidade de uma nova definição para a pós Pós-modernidade - os autores analisam e consideram insuficientes as tentativas de Giles Lipovetsky, Alan Kirby e Nicholas Bourriaud para, posteriormente, questionarem as análises de Jencks, Lyotard, Jameson e Hassan, cujas posições - de acordo com Vermeulen e Van den Akker - podem ser sintetizadas na distinção que Jos de $\mathrm{Mul}^{3}$ apresenta entre a ironia pós-moderna (niilismo abrangente, sarcasmo, desconfiança e desconstrutivismo das grandes narrativas, do singular e da verdade) e o entusiasmo modernista (que abrange do utopismo à crença incondicional na razão). Assim sendo, explicam que, se epistemologicamente o moderno e o pós-moderno estão ligados ao

\footnotetext{
${ }^{2}$ L. Hutcheon, The Politics of Postmodernism (New York/London: Routledge, 2002).

${ }^{3}$ J. de Mul, Romantic Desire in (Post)modern Art \& Philosophy (Albany: State University of New York Press, 1999).
} 
idealismo positivo de Hegel, o metamodernismo está mais para o idealismo negativo de Kant, cuja filosofia da história pode ser sintetizada através da expressão como se, podendo ser descrita da seguinte maneira: "Como Curtis Peters explica, de acordo com Kant podemos ver a história humana como se a humanidade tivesse uma narrativa de vida que descrevesse seu movimento em direção ao seu total potencial racional / social [...] ver a história como se fosse a história do desenvolvimento da humanidade" 4 (2010, p. 5). Em síntese, ao metamodernismo corresponde uma atitude que persegue algo que crê, mas que nunca pode atingir. Já ontologicamente, oscila entre o entusiasmo modernista e a ironia pósmoderna, entre a esperança e a melancolia, a ingenuidade e o conhecimento, empatia e apatia, unidade e pluralidade, totalidade e fragmentação, pureza e ambiguidade em um movimento de permanente balanço sem que isto represente um equilíbrio entre os polos (2010, p.6).

Esse artigo, naturalmente, não ficou imune às críticas, razão pela qual em 2015 os autores publicaram novo texto no site que haviam criado e que leva o nome Notes on metamodernism (www.metamodernism.com) 5 . Nesse texto revisam algumas das questões propostas originalmente e esclarecem que, após participarem intensamente de diversas atividades acadêmicas sobre o tema, desde a primeira publicação, reconhecem a necessidade de um maior esclarecimento de conceitos já apresentados, bem como até o descarte de alguma terminologia não sem por isso sustentar que muitas das críticas recebidas foram oriundas de incompreensões, de mal-entendidos, de interpretações equivocadas e até mesmo de deturpações. E reafirmam que o metamodernismo não é um sistema filosófico, um movimento cultural, um programa teórico, uma técnica literária ou uma estratégia visual, mas sim uma estrutura de sentimento, de certa forma, conceito este próximo da ideia trabalhada por Jameson e Harley, quando eles descrevem o pós-modernismo como uma sensibilidade difundida o suficiente para ser considerada como estrutural.

Para nós, o metamodernismo é uma estrutura de sentimento associada a sensação cada vez mais difundida de que cada um desses debates é iniciado, não como um projeto, mas sim como uma projeção, a premissa sobre qual novos projetos podem ser desenvolvidos. Essa estrutura de sentimento, no entanto, também encontra sua

\footnotetext{
${ }^{4}$ As Curtis Peters explains, according to Kant, "we may view human history as if mankind had a life narrative which describes its self-movement toward its full rational/social potential [...] to view history as if it were the story of mankind's development (Tradução Sophia Bahia)

5 http://www.metamodernism.com/2015/06/03/misunderstandings-and-clarifications/
} 
expressão em muitas línguas formais diferentes que foram descritas em detalhe por outros: a nova sinceridade, o peculiar, o Freak Folk, o Novo Romantismo, o novo materialismo, o realismo especulativo, para citar apenas uns poucos. (Vermeulem $\mathrm{e}$ Akler 2015). ${ }^{6}$

\section{A importância do Novo Romantismo no conceito de metamodernismo}

Manifestações culturais definidas como expressões de um Novo Romantismo são tomadas como exemplo desta estrutura de sentimento definida como metamodernismo. Os autores reconhecem - como Lovejoy e Berlin - a ambiguidade e a pluralidade do romantismo e, como Schlegel, afirmam que este se move entre a ironia e o entusiasmo, o trágico e o sublime, a forma e o disforme, a coerência e o caos e a corrupção e a inocência.

Entre os diversos exemplos deste Novo Romantismo são citadas as exposições Ideal Worlds: New Romanticism in Contemporary Art realizada na SCHIRN KUNSTHALLE FRANKFURT, a retrospectiva de Peter Doing na TATE, bem como a obra de diversos artistas, como: Herzog \& Meuron, Bas Jan Ader, Gregoy Crewdson, David Linch, Olafr Eliasson, Justine Kurland, Mona Hatoum e muitos outros. Apesar dos exemplos, a relação entre Novo Romantismo e metamodernismo não ficou isenta de críticas, assim, no artigo de 2015, os autores, ao tempo em que reconhecem que em muitas das críticas recebidas este Novo Romantismo foi mal interpretado, esclarecem:

Nós concluímos que parece haver alguma confusão em torno da relação entre metamodernismo e Novo Romantismo. Nosso argumento no ensaio de 2010, onde explicamos essa relação, não foi que o metamodernismo pode ser reduzido ao Novo Romantismo, nem que o que é geralmente referido como Novo Romantismo é exclusivo da estrutura metamodernista do sentimento. O que estávamos tentando transmitir ao discutir o metamodernismo por meio do Novo Romantismo, ou Novo Romantismo no contexto do metamodernismo, era que o primeiro, o Novo Romantismo, era apenas uma expressão possível do último, o metamodernismo. Em outras palavras: vários trabalhos reconhecidos como Novo Romantismo

\footnotetext{
${ }^{6}$ For us, metamodernism is a structure of feeling associated with the increasingly widespread sentiment that each of these debates are kickstarted, not as project perhaps as much as a projection, the premise on which new projects may be endeavoured. This structure of feeling, however, too, finds its expression in many different formal languages that have been described in detail by others: the new sincerity, quirky, freak folk, New Romanticism, new materialism, speculative realism, to name just a few. (Tradução Sophia Bahia)
} 
exemplificaram a estrutura metamoderna do sentimento. (https://www.eflux.com/announcements/42102/ideal-worlds-new-romanticism-incontemporary-art $/)^{7}$

Assim sendo, para complementar e exemplificar de forma mais contundente esta estrutura de sentimento que no primeiro artigo apenas se sustentava na identificação de um Novo Romantismo, os autores apontam outras manifestações, que revelam a sensibilidade percebida para formular o conceito de metamodernismo.

Todos esses anos depois, não temos dificuldade em apontar outros desenvolvimentos, que são estilisticamente muito diferentes do Novo Romantismo, porém expressam a mesma estrutura de sentimento: o retorno da História, não como projeto, mas como projeção, uma possibilidade: a Primavera Árabe, Syriza, os Indignados, realismo especulativo, O०O, nova sinceridade, novo normal, peculiares, Freak Folk, pós-Internet e assim por diante. Sentimos que essa confusão também pode ter sido inteiramente nosso erro, à medida que desenvolvemos nosso discurso em torno do metamodernismo a partir de ideias anteriores sobre o retorno do Romantismo na cultura em relação aos desenvolvimentos sociais; isto é, começamos a pensar apenas no metamodernismo como uma estrutura de sentimento, porque passamos a perceber o retorno da sensibilidade do romântico. (https://www.eflux.com/announcements/42102/ideal-worlds-new-romanticism-in-contemporary-art/ ${ }^{8}$

\title{
Causas da constância romântica a partir do argumento de LOWY e SAYRE
}

\author{
Cabe analisar com atenção a identificação deste Novo Romantismo \\ realizada por Vermeulen e Van den Akker, pois a expressão Novo
}

\footnotetext{
${ }^{7}$ We have gathered that there seems to be some confusion around the relationship between metamodernism and New Romanticism. Our argument in the 2010 essay, where we explicated this relation, was not that metamodernism can be reduced to New Romanticism, nor that what is generally referred to as New Romanticism is exclusive to the metamodernist structure of feeling. What we were trying to convey by discussing metamodernism by way of New Romanticism, or New Romanticism in the context of metamodernism, was that the former, New Romanticism, was but one possible expression of the latter, metamodernism. In other words: a number of works recognized as New Romanticism exemplified the metamodern structure of feeling. (Tradução Sophia Bahia).

${ }^{8}$ All these years later, we have no difficulty in pointing out other developments observed by others that are stylistically very different from New Romanticism yet express the same structure of feeling: the return of History, not as project but as projection, a possibility: the Arab Spring, Syriza, the Indignados, Speculative realism, OOO, New Sincerity, New Normal, Quirky, Freak Folk, PostInternet, and so on. We feel that this confusion, too, may well have been our mistake entirely, as we developed our discourse around metamodernism from earlier ideas about the return of Romanticism in culture in relation to societal developments; that is to say, we only began thinking about metamodernism as a structure of feeling because we started perceiving the returning sensibility of the Romantic. (Tradução Sophia Bahia)
} 
Romantismo pode ser entendida como reaparecimento/ressurgir de valores (filosóficos e estéticos) do século XIX, o que pode dar a entender que os valores românticos houvessem desaparecido durante o século $X X$, ou, por outro lado, pode ser entendido como uma nova forma de manifestação desses valores, o que permite considerar que seguiam presentes durante o século XX.

A SCHIRN KUNSTHALLE FRANKFURT é um dos espaços expositivos mais prestigiosos da Europa, já tendo albergado mais de 240 exposições desde sua criação de renomados artistas de diferentes épocas e linguagens como: Yoko Ono, Philip Guston, Géricault, Jeff Koons, Coubert entre tantos outros.

Em 2005, com curadoria de Max Hollein e Martina Weinhart. a SCHIRN apresentou a exposição Ideal Worlds. New Romanticism in Contemporary Art com obras de David Altmejd, Hernan Bas, Kaye Donachie, Peter Doig, Uwe Henneken, Karen Kilimnik, Justine Kurland, Catherine Opie, Christopher Orr, Laura Owens, Simon Periton, David Thorpe e Christian Ward. Em texto de divulgação da exposição, publicado na plataforma $e$ Flux, a SCHIRN afirma:

Em uma sociedade marcada pela crescente mobilidade e minguantes laços sociais, um novo desejo por intimidade e segurança prevalece. A enxurrada de más notícias e imagens de terror faz com que as pessoas anseiem por lugares seguros e perspectivas redentoras. Essa situação também é refletida nas artes visuais de hoje. Após as explorações analíticas do discurso nas décadas de 1980 e 1990 e a reformação da arte em um ato social, somos confrontados com um renascimento do trabalho tradicional para qualquer lugar que nos voltemos. (https://www.eflux.com/announcements/42102/ideal-worlds-new-romanticism-in-contemporary-art/ $)^{9}$

Após apresentar a complexidade do romantismo e sua recorrente má interpretação acrescenta:

[...] Como um sintoma emocional de uma realidade social já informada por convulsões políticas e econômicas no século 19, isto definitivamente fornece um paralelo com a situação atual. A geração atual de artistas se contrapõe à reestruturação dos sistemas políticos e à perda de planos sociais abrangentes com uma estética além do comum. $O$ aspecto da transição cria um vocabulário de anseio

\footnotetext{
9 In a society marked by increasing mobility and waning social bonds, a new yearning for intimacy and security prevails. The flood of bad news and images of terror makes people long for safe places and redemptive perspectives. This situation is also reflected in todays visual arts. After the analytic explorations of discourse in the 1980s and 1990s and the remaking of art into a social act, we are confronted with a revival of the traditional work wherever we turn to. (Tradução Sophia Bahia)
} 
enraizado no movimento romântico histórico. [...]. A solidão como uma perspectiva romântica essencial, esta questão central é tratada principalmente sob a forma de cenários carregados de qualidades simbólicas. A arte contemporânea engloba inúmeras variações deste tema, que vão desde o idílio ameaçado e sua invocação à impressão esmagadora da vastidão exterior e da natureza como um espaço para considerar o transcendental. (https://www.e-flux.com/announcements/42102/idealworlds-new-romanticism-in-contemporary-art/ $)^{10}$

E termina afirmando:

[...] Considerando estes contextos, o Romantismo apresenta-se como uma abordagem que foi retomada, continuada e transformada em uma variedade de linhas e estratégias de apropriação pelos artistas de hoje que visam muito mais do que reviver uma gama de motivos salvos como adereços melancólicos de um passado glorioso. O romantismo de hoje é um meta-romantismo que trabalha com meios pósmodernistas. Desdobra-se uma síntese de passado e presente, emoção e discurso. (https://www.e-flux.com/announcements/42102/ideal-worlds-new-romanticism -in-contemporary-art/) $)^{11}$

Como é possível observar, segundo a SCHIRN KUNSTHALLE FRANKFURT, a presença do romantismo na arte contemporânea apresenta motivações e características bastante semelhantes com as atribuídas por Vermeulen e Van den Akker para definir o metamodernismo e, ao afirmarem que o romantismo foi retomado, subentendem que durante um período não esteve presente na arte.

Agora bem, um ponto que merece destaque na leitura da SCHIRN é a sua afirmação de um paralelo entre a situação política e econômica dos dias atuais e as convulsões do século XIX. De fato, ao se tomar a formulação de Michel Löwy e Robert Sayre, em seu trabalho Revolta e Melancolia (2015), este paralelo é a chave para entender não apenas a presença de elementos

\footnotetext{
${ }^{10}$ Como um sintoma emocional de uma realidade social já informada por convulsões políticas e econômicas no século 19, isto definitivamente fornece um paralelo com a situação atual. A geração atual de artistas se contrapõe à reestruturação dos sistemas políticos e à perda de planos sociais abrangentes com uma estética além do comum. O aspecto da transição cria um vocabulário de anseio enraizado no movimento romântico histórico. [...]. A solidão como uma perspectiva romântica essencial, esta questão central é tratada principalmente sob a forma de cenários carregados de qualidades simbólicas. A arte contemporânea engloba inúmeras variações deste tema, que vão desde o idílio ameaçado e sua invocação à impressão esmagadora da vastidão exterior e da natureza como um espaço para considerar o transcendental. (Tradução Sophia Bahia).

${ }^{11}$ Considering these contexts, Romanticism presents itself as an approach which has been taken up, continued, and transformed in a variety of lines and strategies of appropriation by todays artists who aim at much more than at reviving a gamut of motifs saved as melancholy props from a glorious past. Today's Romanticism is a meta-Romanticism working with postmodernist means. It unfolds a synthesis of past and present, emotion and discourse. (Tradução Sophia Bahia).
} 
oriundos do romantismo na arte contemporânea, mas a sua presença constante ao longo de todo o século XX.

Os principais estudiosos do romantismo - como Isaiah Berlin, que se apoia em Vermeulen e Van den Akker, mas também Alfredo Paz entre outros sustentam que a diversidade de manifestações surgidas ao longo do XIX, como decorrência das ideias românticas, inviabiliza a formulação de um conceito de Romantismo que englobe a todas as contradições. Por outro lado, Löwy e Sayre apontam uma postura diferente, defendendo a possibilidade de definição através da aglutinação das variadas vertentes românticas por um ponto comum a todas, a saber: sua contraposição aos ideais e aos valores que resultaram da junção entre ciência e capital surgidos com a revolução industrial.

Para fundamentar sua afirmação de possibilidade da definição do romantismo, Löwy e Sayre partem de Max Weber, que sustentava que as quatro características principais da modernidade - o espírito de cálculo, o desencantamento do mundo, a racionalidade instrumental e a dominação burguesa - são inseparáveis do aparecimento do espírito capitalista (2015:39). Para os autores, o romantismo deve ser entendido como um todo complexo de múltiplas facetas. Um todo que é reação dentro de uma totalidade que o capitalismo é, enquanto modo e relações de produção, o principal unificador e gerador.

Esse sistema socioeconômico é caracterizado por diversos aspectos: a
industrialização, o desenvolvimento rápido e conjugado da ciência e da tecnologia
(traço que define a modernidade de acordo com o Petit Robert), a hegemonia do
mercado, a propriedade privada dos meios de produção, a reprodução ampliada do
capital, o trabalho "livre", uma divisão intensificada do trabalho. E, em torno dele,
desenvolvem-se fenômenos de "civilização" inteira ligados a ele: a racionalização, a
burocratização, a secularização, a "reificaçãa". [...] O Romantismo nasce de uma
oposição a essa realidade capitalista/moderna - às vezes designada na linguagem
romântica simplesmente como "realidade". (2015, p. 40)

Assim sendo, a sensibilidade romântica não apenas é representação de uma revolta contra valores da civilização capitalista como é também veículo que contribui aos impulsos anticapitalistas. Interessante destacar também que, para Löwy e Sayre, o romantismo surge como uma crítica moderna da modernidade, pois os românticos também são altamente influenciados por sua época, sendo de fato uma "autocrítica da modernidade". Este repúdio a realidade social se deve da percepção da perda de determinados valores, que se concentram em torno de dois polos opostos, "mas não contraditórios". Um é o da valorização da subjetividade, da riqueza e da complexidade humana, da afetividade e da 
liberdade e da imaginação. O outro é o desejo de unidade e totalidade do eu (com sua subjetividade) com a natureza e a coletividade humana.

Agora, ao se perguntar por que o romantismo conseguiu atingir camadas sociais tão diversificadas, Löwy e Sayre discordam das diversas análises sociológicas que reduzem as posições românticas a ser causa da opressão no nível econômico. Para os autores, a resposta está na intelligentsia: "grupo de indivíduos de origens sociais diversas, cuja unidade e autonomia (relativa) resultam de uma posição comum no processo de produção da cultura" (2015, p.115). Löwy e Sayre consideram evidente que a intelligentsia romântica represente valores de uma tradição da intelligentsia, cujo modo de vida é hostil aos valores burgueses industriais, sendo composta por escritores independentes, religiosos, teólogos, poetas, artistas e lideranças universitárias. E sendo o capitalismo um sistema, cujo funcionamento é determinado por valores quantitativos, é natural que a contradição entre os valores da intelligentsia tradicional e o meio ambiente social moderno seja geradora de conflitos e de revoltas. A recusa em aceitar a limitação da influência do ideário romântico como causa da opressão econômica se deve ao entendimento de que além de ser geradora de um reducionismo, por limitar a audiência romântica a "bolsões de resistência", esta não dá conta de explicar a permanência deste ideário.

Se isso fosse exato, essa visão de mundo seria um fenômeno em declínio, condenado a desaparecer pelo próprio desenvolvimento da modernidade. Ora, não é bem assim: não apenas uma parte significativa da produção social contemporânea é profundamente influenciada por ela, como assistimos a ascensão de novos movimentos sociais com forte matriz romântica. (2015, p.117)

De fato, a opressão econômica não pode ser a única justificativa para a permanência dos valores românticos, uma vez que, apesar da existência de desigualdades sociais e do aumento da distância entre os mais ricos e os menos ricos, de forma geral, a sociedade contemporânea ocidental possui um acesso à moradia, à alimentação, à saúde, ao vestuário e à educação como nunca antes na história, ou seja, a realidade dos trabalhadores urbanos e rurais no mundo Ocidental se distancia muito da realidade do final do século XVIII e todo o XIX. Naturalmente, a ampliação significativa na melhoria das condições de acesso acima descritas não impede - nem sequer desautoriza - a identificação com os valores românticos, nem a busca por melhores condições econômicas. Quanto maior a educação, maior a compreensão do funcionamento do sistema político e econômico e, consequentemente, maior a exigência por uma melhor remuneração e condições sociais de vida, condições estas cujos valores não se resumem a um maior salário ou poder aquisitivo, mas estão 
relacionadas às possibilidades de uma melhor qualidade de vida com mais tempo de lazer, maior acesso aos bens culturais, melhor e mais disponibilidade de acesso aos cuidados da saúde, de educação atualizada e de melhoria permanente das condições de trabalho, etc. Como cantava Arnaldo Antunes: A gente não quer só comida. A gente quer comida, diversão e arte. Um exemplo claro de que a melhoria das condições econômicas não conduz ao abandono das ideias contrárias a visão de mundo científico-capitalista é o fato de que incontáveis artistas influenciados pelo ideário romântico, que adquiriram reconhecimento e fortuna, não abandonaram, pela aquisição de riquezas, os valores que alimentaram suas produções artísticas. Se somar a este fato, ou melhor, se relacionar com este a influência do marxismo - e não se deve esquecer que boa parte dos artistas modernistas na Europa e América Latina, durante a primeira metade do século $X X$, era vinculada ao Partido Comunista - então, não resta dúvida de que o romantismo nunca deixou de estar presente na cultura ocidental - e além, desde seu surgimento.

Tanto Marx quanto Engels tinham em alta conta certos críticos românticos do capitalismo industrial, em relação aos quais tinham uma dívida intelectual indiscutível. A obra de ambos foi significativamente influenciada não somente por economistas românticos como Sismondi ou o populista russo Nikolai Danielson, com o qual se corresponderam durante vinte anos, mas também por escritores como Dickens e Balzac, por filósofos sociais como Carlyle e por historiadores da comunidade antiga como Maurer, Niebuhr e Morgan - sem falar dos socialistas românticos como Fourier, Leroux ou Hess. Na realidade o romantismo é uma das fontes esquecidas de Marx e Engels, uma fonte que talvez seja tão importante para o trabalho deles quanto o neo-hegelianismo alemão ou o materialismo francês (2015, p. 120-121).

Quando Vermeulen e Van den Akker citam - como exemplo desta nova sensibilidade - os movimentos sociais como Syriza (que ocorreu na Grécia e, posteriormente, se transformou em partido político), e o $15 \mathrm{M}$ espanhol (The Indignados, do qual surge o partido político espanhol Podemos) nada mais apontam que novas formas de mobilização e de organização social (possível por redes sociais em novas tecnologias), cuja matriz ideológica deve em muito ao marxismo, uma vez que ambos os movimentos, muito mais do que criticar e denunciar apenas o empobrecimento das classes médias e trabalhadoras, também criticam a visão política dos Governos, que - submetidos e justificando-se pela pressão do fluxo de capitais - mantém uma política que favorece, preponderantemente, ao mercado econômico em detrimento da qualidade de vida social, através da retirada de benefícios sociais, de direitos trabalhistas conquistados, da redução em investimentos na saúde, na educação e na cultura, enquanto socorrem bancos que perdem fortunas em práticas especulativas. 
É ingênuo - ou mal-intencionado - o entendimento de que aqueles movimentos sociais tenham sido fomentados por sindicatos e partidos de esquerda. Embora as questões econômicas concretas estivessem entre as primeiras palavras de ordem, o que verdadeiramente os jovens pleiteavam - e seguem ainda parcialmente pleiteando através de representação política - eram perspectivas diferentes daquelas que lhes estavam e estão sendo oferecidas pelos Governos Ocidentais através de suas políticas.

Características definidoras da pós-modernidade como a ironia, a desconfiança e o desconstrutivismo das grandes narrativas e da verdade, quando somadas com as políticas econômicas dos Governos Ocidentais e a velocidade das transformações sociais causadas pela revolução digital, produzem um ambiente de incerteza e de ausência de perspectivas, que gera uma exacerbação niilista contra a qual, não é de surpreender, os valores românticos se insurgem, comparecendo não como válvula de escape para um mundo impossível, mas como resistência e lembrança de valores que definem o humano.

Assim sendo, e sem excluir a questão econômica, concorda-se então que são fundamentalmente valores que giram em torno da valorização da subjetividade e do desejo de unidade - por serem antagônicos aos valores da lógica científico-capitalista - os que sustentam a permanência ao longo do século XIX, XX e início do XXI de parte do ideário romântico.

Já foi suficientemente evidenciada por Rosemblum (1993) a influência do ideário romântico na arte ao longo do XIX e primeira metade do XX, tanto na Europa como nos EEUU. Artistas como Van Gogh, Gaugin, Nolde, Mondrian, Kandinsky são exemplos paradigmáticos, mas de forma geral o Simbolismo, o Fauvismo, o Expressionismo alemão, o Abstracionismo e o Expressionismo abstrato são impossíveis de serem compreendidos sem considerar os valores oriundos do romantismo. E, se estender para além da estética e se incluir os comportamentos artísticos da rebeldia e da boemia, então o romantismo deve ser considerado em um leque muito mais amplo de ressonância. A própria negação da autoria através de trabalhos coletivos - tão presente na pós-modernidade - surge no romantismo como uma proposição formulada teoricamente na Revista Athenaeum, fundada pelos irmãos A. W. e F. Schlegel em 1789. Em todos estes exemplos são outros valores, que não o econômico, os que animam as proposições. 


\section{Considerações finais}

Embora a leitura dos artigos de Vermeulem e Van der Akker deixe margem para um entendimento de que o Novo Romantismo representa um ressurgimento, tenta-se aqui evidenciar que a presença de elementos oriundos do ideário romântico, na metade do século XX e início do XXI, não é novidade e nem muito menos surpresa, mas uma recorrência, pois nunca deixou de se fazer presente, sendo natural seu reflexo na arte contemporânea, assim como em outras manifestações culturais e sociais. Isto não significa que a identificação e o uso do Novo Romantismo na fundamentação do metamodernismo, por parte de Vermeulem e Van der Akker, esteja equivocada, pois o que eles identificam não é uma reprodução do romantismo do Século XIX ou de sua herança no modernismo do XX. É mais a apropriação - que é uma das características estratégicas das estéticas pós-modernistas - de elementos oriundos do romantismo que estavam presentes na cultura, mas que se chocam com pressupostos e valores pós-modernistas, quando colocados juntos. Disso resulta que Vermeulem e Van der Akker conseguem reconhecer, nesta prática (e em outras) de vários artistas, semelhanças e diferenças com o pós-modernismo stricto sensu para então poder afirmar que esta estrutura de sentimento - que é o metamodernismo - oscila como um pêndulo sem buscar o equilíbrio dos polos.

Desde sua publicação, em 2010, a formulação de metamodernismo apresentada por Vermeulem e Van der Akker tem ganhado espaço através de diversos artigos acadêmicos nas áreas de artes visuais, música, cinema, ciências sociais, moda e cultura em geral - e, ainda, que não isento de críticas - estes escritos têm buscado dar maior exemplificação ao conceito.

Já o estudo de Michel Löwy e Robert Sayre permite compreender que a permanência dos valores românticos transcende às manifestações artísticas, uma vez que se encontra disseminada em valores culturais, que atuam como resistência aos valores surgidos da junção de uma visão cientificista com a lógica capitalista, impondo para a sociedade um conjunto de práticas desumanizadoras. 


\section{Referências}

HOLLEIN, Max and WEINHART, Martina. Ideal Worlds: New Romanticism In Contemporary Art. Disponível em https://www.eflux.com/announcements/42102/ideal-worlds-new-romanticism-incontemporary-art/ Acesso em: 13 abr. 2018.

LÖWY, Michel e SAYRE, Robert. Revolta e Melancolia. São Paulo: Boi tempo, 2015.

ROSEMBLUM, Robert. La pintura moderna y la tradición del romanticismo nórdico. Madrid: Alianza Editorial, 1993.

VARGAS, Antonio. Nostalgia e morte: a estratégia romântica para viver. Revista Brasileira de Psicanálise, v. 51 n³ 3, 2017.

VELMEULEN, Timotheus; VAN DEN AKKER, Robin. Notes on metamodernism. Journal of Aesthetics \& Culture. V.2, 2010. DOI 10.3402/jac.v2i0.5677. Versão portuguesa publicada em Arte \& Ensaios (PPGAV/EBA/UFRJ) n. 34, dezembro 2017. Disponível em https://revistas.ufrj.br/index.php/ae/article/viewFile/14524/9727

VELMEULEN, Timotheus; VAN DEN AKKER, Robin. Misunderstandings and clarifications. $2015 . \quad$ Disponível em: http://www.metamodernism.com/2015/06/03/misunderstandingsand-clarifications/ Acesso em: 13 abr. 2018. 